\title{
Civic crowdfunding: a new opportunity for local governments
}

\begin{abstract}
In civic crowdfunding, local communities are asked to financially contribute to projects aimed at the regeneration of an area. Usually a local government acts as a co-funder. This paper employs a fuzzy set qualitative comparative analysis to discover which conditions are combined and may result in the collection of a significant amount of funds. Five conditions were selected: the nature of project, the number of backers, the number of rewards, the percentage of backers that did not require a reward and the percentage of rewards not required during the fundraising campaign. The study used a sample of 40 Italian successful civic crowdfunding rounds sponsored and match-funded by a local government. The nature of the projects and the presence of rewards seem to emerge as critical influencing factors. These findings open up further investigations on the attitudes of civic backers towards rewards and on the charitable nature of civic fundraising.
\end{abstract}

Keywords: civic crowdfunding; local government; local communities; reward; fsQCA 


\section{Introduction}

Local governments and private foundations have traditionally managed the funding of projects aimed at territorial and social development by mainly following a top-down approach, which has not succeeded in properly engaging citizens and local communities (European Crowdfunding Network, 2018). In the context of increasing public sector budget constraints, civic crowdfunding has attracted increasing interest because of its potential to become both a support mechanism for public finance and a way to respond to citizens' increasing desire for participation in public life (Stiver et al., 2015a). Indeed, this type of crowdfunding is defined as civic since it involves citizens, grouped to form local communities, which contribute to the regeneration of a territory with their engagement, time, ideas and financial resources. Civic crowdfunding needs to be distinguished from other types of crowdfunding since it pursues an objective of general interest and mainly concerns place-based projects (Charbit \& Desmoulins, 2017) through which citizens, mainly in collaboration with the public sector, fund projects aimed at public utility. In civic crowdfunding campaigns, public goods or services of public interest are backed by individuals, foundations or businesses, with total or partial (match-funding) substitution of funding by the public sector. Contributions by these backers are completely voluntary and the project is considered successfully financed if an adequate level of financing has been collected (Hummel, 2016). Consequently, the relationships that arise between the public sector, local communities, social investors and crowdfunding web platforms might be considered a collaborative means to achieve important goals in terms of the fulfilment of projects of public interest and promotion of local development with a sustainable and inclusive approach.

Civic crowdfunding has changed the landscape of fundraising for charitable purposes since it is 'a unique type of crowdfunding that garners funds for civic causes, such as urban renewal, neighbourhood green space, and community events' (Brent \& Chan, 2019, p. 2143). By analogy with studies on other types of crowdfunding models, previous academic research on civic crowdfunding has mainly focused on different drivers that can influence the success of civic crowdfunding campaigns (see among others, Brent \& Lorah, 2019; Doan \& Toledano, 2018; Hassna et al., 2018), while only less attention has been devoted to the nature of civic project searching for funds (Brent $\&$ Lorah, 2019; Lee et al., 2019). Notwithstanding, the delimitation and comprehension of this phenomenon is far from well-defined. Indeed, civic crowdfunding is a multifaceted phenomenon that has not yet received a rigorous examination. Some additional aspects and complexities need to be considered, with special reference to the nature of the civic initiatives searching for funds and the business model of the crowdfunding platforms involved in civic fundraising campaigns. Civic initiatives sponsored and match-funded by local public governments might have both for-profit and 
not-for-profit natures and their scale may vary considerably. Moreover, civic rounds can be run on both generic reward-based platforms and civic dedicated platforms. The business model and operational framework of these two different types of platforms is considerably different. Dedicated civic crowdfunding platforms charge relatively small fees for their services in comparison to rewardbased platforms, but they ask potential backers for optional gratuities when contributing to a campaign (Brent \& Chan, 2019). On the other hand, the presence of rewards mut be considered an essential component of the investment proposal on reward-based platforms.

In this context, this paper aims to shed light on the nature of civic projects and on the role played by the presence of rewards in these campaigns to investigate the attitudes of backers to such rewards. The paper employed a sample of 40 civic crowdfunding rounds sponsored and match-funded by a local government and successfully funded on an Italian reward-based platform.

The study provides new insight into the factors able to influence the fundraising process of civic initiatives by investigating the complexity of this market, comprised of both for-profit and not-forprofit projects, and the role played by the reward mechanism in the engagement of local community.

The remainder of the paper is organised as follows. In Section 2, the theoretical framework is presented. In Section 3, the key elements of the civic crowdfunding market and the dataset are described, and the methodological aspect are explained. Section 4 focuses on the results emerging from the analysis, while Section 5 presents a discussion and Section 6 consists of the main conclusions, policy implications and research limitations.

\section{Theoretical framework}

Civic crowdfunding is a type of crowdfunding through which local communities, often in collaboration with local governments, propose and fund projects that aim to provide local area improvement projects or a community service (European Crowdfunding Network, 2018).

Civic crowdfunding campaigns are a type of fundraising in which, directly or indirectly, the project searching for funds benefits from government funds or sponsorship (Bernardino \& Santos, 2016). Usually, civic crowdfunding involves a fundraising method of total or partial (match-funding) substitution of funding by the public sector. As far as Europe is concerned, many local authorities (cities and regions) have experimented with different roles within the civic crowdfunding scheme, ranging from simple sponsors to co-funders (European Crowdfunding Network, 2018). Thus, civic crowdfunding can be seen as both an alternative tool for supporting public finance and a new way of interacting between citizens, the public sector and crowdfunding web platforms (Miglietta et al., 
2013). The potential of civic crowdfunding for boosting economic outcomes and realising a more democratic, transparent and efficient allocation of financial resources has been widely highlighted (Passeri, 2017). Great potential has also been acknowledged for civic crowdfunding as far as nonfinancial benefits are concerned, such as facilitating networking and encouraging collaboration between citizens and the government (Stiver et al., 2015b).

In spite of the considerable flexibility allowed by match-funding schemes in the crowdfunding market, starting from the framework proposed by Davies (2014) and then by Charbit and Desmoulin (2017), four different approaches to public sector involvement have been proposed: the sponsor model, the manager model, the curator model and the facilitator model. In the sponsor model, the local public administration runs its own campaign via an existing civic crowdfunding platform. In the manager model, the local public administration creates its own crowdfunding platform to fund projects aimed at fostering the development of its territory. Usually, these platforms are generic crowdfunding platforms where both for-profit/entrepreneurial and not-for-profit projects can be promoted. In the curator model, the local public administration, using a generic reward crowdfunding platform with a special exclusive civic section, selects and proposes initiatives to be funded. Finally, in the facilitator model, the local public administration assumes the role of facilitating citizens' initiatives by supplying technical and financial support and co-screening and/or co-designing the projects searching for funds.

According to Lee et al. (2016), if the proponent of the project is a public authority, the crowdfunding round is defined as public rather than civic. In public crowdfunding, the public body is not only a sponsor and a co-funder of the initiative searching for funds, but also acts as a proponent. It first conducts an internal assessment and selection of potential projects to finance through crowdfunding, then steps forward as a proponent of the fundraising initiative.

\subsection{Nature of civic crowdfunding projects}

Civic crowdfunding is not considered a substitute for traditional government spending on infrastructure since civic crowdfunding rounds are not typically employed to fund large scale projects (Brent \& Lorah, 2019). The projects collecting funds through civic fundraising must result in an improvement in the lives of the community members and represent a 'shift to a more participatory form of urban planning' (Brent \& Lorah, 2019, p. 122). The projects can have a profit or a not-forprofit nature, since civic crowdfunding is used also by social entrepreneurs to fund their social enterprises (Calic \& Schevchenko, 2020; Lee et al., 2019). Social entrepreneurs often have limited access to traditional capital providers and this problem seems to sharpen 'when social ventures need 
capital to invest in commercial activities that generate earned income' (Calic \& Mosakowski, 2016, p. 739).

Pitschner and Pitschner-Finn (2014), in their study on the factors related to the success of social crowdfunding campaigns on reward-based platforms, distinguished between for-profit and not-forprofit projects, and found that non-for-profit projects have a higher probability of success and received higher average contributions in comparison with for-profit projects.

Within the context of prosocial lending, Allison et al. (2015) concluded that backers are positively influenced by narratives that describe the projects as an opportunity to help others, and less positively by narratives that highlight the project as a business opportunity.

Despite the awareness that the civic crowdfunding market comprises projects of different nature, little attention has been paid to the complexity that this characteristic entails, also in terms of the amount of funds requested and raised. Consequently, taking into consideration that in a generic reward-based crowdfunding platform both for-profit and not-for-profit projects coexist, it can be supposed that a relationship exists between the amount of funds raised and the nature (for-profit versus not-for-profit) of the project. In line with this theoretical background, a first proposition is set:

Proposition 1: The nature of the project (not-for-profit versus for-profit) in a civic crowdfunding round has implications for the results of the fundraising campaign in terms of the amount of funds raised.

\subsection{Backers and rewards}

Crowdfunding bases its success on the potential to bring together as many backers as possible interested in raising funds for a project (Martinez-Climent et al., 2019). A specific interest in a project can be driven by geographical and relational closeness. Though this condition of interest is essential for any type of crowdfunding (Hui et al., 2014), it seems to be particularly important in the case of civic fundraising campaigns because by supporting projects aimed to stimulate the social and cultural development of an area civic crowdfunding has its roots in a sense of belonging to a community or place, as well as the benefits expected from the project. Josefy et al. (2016) stated that 'crowdfunding communities are first and foremost communities of interest' (p. 176) and that the interest in the project depends on the match between the project's aim and the cultural values of its target community.

Civic crowdfunding often involves participation from backers whose aim is to stimulate the social and territorial development of geographical areas to which they feel themselves connected. More 
precisely, backers are of two types: those who fund and enjoy the benefits of a project (individual self-interest) and those motivated by a broader interest in financing a good or service despite not having the opportunity to enjoy the benefits directly for reasons of geographical location (self and others interest) (Stiver et al., 2015b). The decision to support civic initiatives usually involves 'a strong personal interest-driven mechanism based on knowing each other' (Sedlitzky \& Franz, 2019, p. 40). Moreover, people living in the same area tend to have similar preferences, often leading to less controversy in project choice (Hudik \& Chovanculiak, 2018). According to the aforementioned arguments, the following proposition is presented:

Proposition 2: The number of backers involved in a civic crowdfunding round has implications for the result of the fundraising campaign in terms of the amount of funds raised.

Backers involved in civic crowdfunding campaigns usually expect a non-financial or emotional reward since they are driven by a sense of engagement and belonging towards local territories (De Falco et al., 2015). Intrinsic motivation is usually associated with a donation investment approach, in which investors do not expect a tangible or material reward in exchange for their financial contribution (Tomczak \& Brem, 2013). Backers involved in civic crowdfunding campaigns seem to act as donors, who see their return only in form of happiness because their funds are used for honourable causes. Indeed, behaviours performed in order to obtain a reward (external motivation) are not relevant for donors acting on crowdfunding platforms (Wang et al., 2019). In the context of private contributions to public goods, Burtch, Ghose and Wattal (2013) found evidence that altruism is a key incentive to foster contributions by potential investors. Backers involved in civic crowdfunding campaign are interested in ideas and the core values of the projects being financed (Lehner, 2013) and in the positive capital impact of their investment in term of economic, social and environmental values (McWade, 2012). Consequently, they expect a certain social impact or simply a noble feeling as a reward (Lehner, 2013). If rewards exist, they should have a symbolic value that is lower than the donation amount (Sedlitzky \& Franz, 2019). Brent and Chan (2019) analysed the 'crowding out' phenomenon in civic markets. They demonstrated the presence of this phenomenon in charitable initiatives since they found a strong negative relationship between donations to the civic crowdfunding platform and individual fundraising rounds run on the platform.

In line with the sense of belonging that is the distinguishing feature of backers in civic campaigns, civic crowdfunding campaigns can be run both on dedicated civic platforms and on reward or donation- based crowdfunding platforms. To gain an in-depth understanding of the attitude of civic backers towards rewards, academic research on factors able to influence the successful conclusion of a civic round must be taken into consideration. Different types of factors have been analysed. 
The influence of lead donors on the performance of civic fundraising campaign was studied by Hassna et al. (2018), who focused on the impact that the presence of these donors can have on subsequent fundraising, and also investigated as how this influence varies depending on the lead donors' organisation type (business, public sector or NGO) (Zhao et al., 2020). They found that attracting lead donations from established organisations, especially NGOs, is a factor that influences the success of campaign fundraising.

Analysing the January-February 2016 Awaroa/Abel Tasman beach campaign in New Zealand, Doan and Toledano (2018) reached interesting conclusions regarding the factors needed for the success of civic crowdfunding campaigns. Their findings highlighted the factors that are key to a successful crowdfunding campaign: 'high consensus on a community cause based on shared values and concerns among members; positive and inclusive discourse running consistently throughout the campaign; utilisation of social media channels and features, amplified by support from traditional media to maintain campaign momentum; close collaboration between campaign organisers and civic crowdfunding platform' (p. 43).

Brent and Lorah (2019) found that while the project's neighbourhood features are not strong drivers of total donations for civic initiatives, distance plays an important role. They also concluded that the backers' social networks are critical for backers 'that live far away from the project site but have strong ties to the projects' community and/or campaign leader' (p. 129).

Lee et al. (2019) explored how linguistic style and message substance influence persuasion in civic crowdfunding. They concluded that extensive use of social language does not influence funding performance; indeed, such language reduces the likelihood of project success. Moreover, they also claimed that the funding outcome is influenced by risk language.

By studying a successful civic crowdfunding campaign in an Italian university, Colasanti et al. (2018) found that key factors for success include effective communication and the presence of feelings of belonging to the project/initiative searching for funds. Because of the intrinsic motivations that push citizens to financially support a civic campaign, they explored the interest of potential backers in receiving a reward. It is particularly relevant to underline how the great majority of the respondents to their questionnaire claimed they did not need a reward. The inclusion of gifts might also be a strategy for collecting more money. Falk (2004) investigated the relevance of gift exchange for charitable donations and observed that including gifts has a strong and systematic influence on the frequency of contributions. 
Sedlitzky and Franz (2019) claimed that if a campaign is mainly supported by local communities, the interest in a reward might be critical. Indeed, motivation to support a campaign tends to differ between backers who lives near the place where the initiative will be implemented and backers who live far away from it; direct and personal rewards that arise from the implementation of projects decrease as distance increases. Davies (2015) provides a very interesting interpretation of the role played by rewards in civic crowdfunding. He claimed that offering rewards at particular levels 'undermines the notion that crowdfunding is a process that anticipates equal participation by all, and incentivises backers to contribute different amounts' (p. 346).

On the other hand, on reward-based crowdfunding platforms it is possible that some investors back a project because of the rewards offered. A project with a large number of rewards is likely to raise more funds since it attracts a broader potential community by offering a wider choice of rewards (Calic \& Mosakowski, 2016).

In line with the theoretical background on the factors influencing civic crowdfunding, and considering that a campaign can be run on a generic reward-based platform, as in the case study selected, the following propositions are defined:

Proposition 3: The number of rewards offered has implications for the result of the fundraising campaign in terms of the amount of funds raised.

Proposition 4: The percentage of backers that do not require a reward has implications for the result of the fundraising campaign in terms of the amount of funds raised.

Proposition 5: The percentage of rewards not required by backers has implications for the result of the fundraising campaign in terms of the amount of funds raised.

\section{Methodology}

\subsection{Sample and data}

Usually, small-scale projects (in comparison with local public government capital budgets) are funded through civic crowdfunding, including 'improvements to local parks; installations of green infrastructure and community gardens; streetscape enhancements such as crosswalks and bike lanes; and public art ... volunteer cleanup days; youth after-school programs; and street festivals' (Brent \& Lorah 2019, p. 122). It is not possible to define a unique and standardised list of projects since there is a wide spectrum of potential initiatives. 
In the European context, combined funding has usually been awarded to projects in the areas of social inclusion, the environment, cultural and creative industries, and also entrepreneurship, agriculture and health research (European Crowdfunding Network, 2018).

Taking into consideration the presence of match-funding schemes, in Italy during 2018, civic-based projects collected about 4 million euro (Bacigalupi, 2019; STARTEED, 2019). It is important to note that among the Italian cities that invested in crowdfunding, most of the fundraising campaigns were directly promoted by the city administration; in a small number of cases, the local public administration acted as a project partner. Moreover, in some cases, recourse to crowdfunding campaigns is a part of a wider public programme aimed at the promotion of a 'Smart City' and innovation within a certain geographical area (STARTEED, 2019). Finally, it is interesting to note that the majority of local public administrations involved in crowdfunding initiatives are cities, both large and small; in one case, a region was the registered partner.

In this context, the dataset used in this research comprises 40 civic projects successfully funded on an Italian reward platform (Eppela) from 2016 to 2019. All these civic initiatives were aimed at developing goods or services of public utility and were sponsored and match-funded by a local public government. These local governments were mainly cities of varying sizes, but also included one region.

With regard to the nature of the projects, the dataset is largely comprised of not-for-profit initiatives searching for funds. Not-for-profit initiatives accounted for $75 \%$ of the sample, and for-profit projects $25 \%$. The average target amount was about 51,000 euros, with a minimum and a maximum amount of 6,000 and 150,000 euros, respectively. Except for one case, the campaigns were not overfunded, meaning that the funding round was successful, but raised no more than the amount requested; even for the single overfunded case, the percentage of overfunding was low (1.05\%). The average number of backers per project was 73 , with a minimum and a maximum of 37 and 235 , respectively.

\subsection{Method: $f_{S} Q C A$}

\subsubsection{Outcome, causal conditions and calibration}

A fsQCA approach was adopted to draw a map of contingency factors that may influence the fundraising results of civic crowdfunding campaigns in terms of amount of funds raised. The contribution of this research is therefore not only its content, but also its methodology. FsQCA allows the discovery of different paths that lead to the same outcome, in contrast to a unique solution 
presented by traditional quantitative methods such as structural equation analysis (Huarng et al., 2020; Lv et al., 2020).

In QCA, necessary and sufficient conditions are distinguished in recognition of the fact that different sets of conditions may lead to the same outcome (Ragin, 2008). Indeed, QCA is a method of empirical analysis that assumes that multiple and different causal paths to a desired outcome may coexist and be relevant to explain the outcome in a different way (Fiss, 2007). Moreover, QCA is a suitable method for dealing with small datasets, as is the case of the dataset employed in this study (Rihoux \& Ragin, 2009; Schneider \& Wagemann, 2006).

Different phases are present in the fsQCA methodology: i) identification and calibration of the outcome and the conditions; ii) identification and analysis of the necessary conditions; iii) definition of a truth table that lists all possible logical combinations that lead to the presence or the absence of the outcome, along with the cases related to these; and iv) identification and analysis of the sufficient conditions.

To perform the analysis, first, the outcome must be defined. In this case, the outcome represents the amount of funds raised; the presence of the outcome means that a substantial sum of funds was raised, while the absence of the outcome means that a low amount of funds was raised. Since the sample comprises almost solely campaigns successfully closed and not overfunded, the outcome can be also considered a measure of the scale dimension of the project.

In addition to the outcome, the conditions able to influence the result of the campaign must be selected. According to the theoretical framework described above, five antecedent conditions were set: nature of project (NP), number of backers (BACK), number of rewards (REW), percentage of backers that did not require a reward (BACKNOREW), and percentage of rewards not required/used during the fundraising campaign (REWNOUSED). Table 1 provides a description and codification of the outcome and the conditions.

$<$ Insert Table 1 here $>$

Except for the condition NP, which is a crisp condition ( 0 or 1$)$, all other conditions and the outcome must be calibrated. In the calibration process, the raw data are rescaled into scores ranging from 1 to 0 (Ragin, 2008), identifying the cases of full membership and full non-membership. Usually, 
calibration criteria are based on theory and the structure of the dataset. However, when there is a lack of previous research on the topic, empirical calibration is recommended and the data are calibrated using percentile splits of the sample (Crilly, 2010; Lewellyn \& Fainshimdt, 2017).

The outcome (the amount of funds collected during the fundraising campaign) is a continuous variable that must be calibrated. To do this, the $10^{\text {th }}$ and the $90^{\text {th }}$ percentiles were used as thresholds for full non-membership and full membership, respectively, while the median value was used as the crossover point. Table 2 shows the thresholds used for the process of calibration.

A similar process is adopted for the calibration of the condition BACK and REW. The condition NP is crisp and does not need to be calibrated: type of project is coded 1 if it is not-for-profit and 0 if it is for-profit.

$<$ Insert Table 2 here $>$

The conditions BACKNOREW and REWNOUSED are percentage values that hence already range from 0 to 1 , and do not require calibration.

\section{Results}

With fsQCA, it is possible to identify how conditions combine and causally lead to the outcome (i.e., the presence of a high level of collected funds) and to the absence of the outcome (i.e., the presence of a low level of collected funds). Consequently, two models can be specified as follows:

Model A: OUT = f $(\mathrm{NP}, \mathrm{BACK}, \mathrm{REW}, \mathrm{BACKNOREW}, \mathrm{REWNOUSED})$

Model B: $\sim$ OUT $=\mathrm{f}(\mathrm{NP}, \mathrm{BACK}, \mathrm{REW}, \mathrm{BACKNOREW}, \mathrm{REWNOUSED})$

where the symbol $(\sim)$ indicates the absence of an outcome or condition.

\subsection{Analysis of necessary conditions}

The first step of a fsQCA consists of the analysis of the necessary conditions - the conditions that must occur to obtain the outcome or the absence of the outcome. Table 3 shows the results of this analysis. According to Schneider and Wagemann (2012), to consider a condition necessary, consistency must be higher than 0.9 . 
$<$ Insert Table 3 here $>$

For the first model (i.e., high amount of funds raised), no necessary condition exists; indeed, no condition has a consistency score higher than 0.9. For the second model (i.e., low amount of funds raised), one necessary condition exists ( REWNOUSED). This means that to raise only a low level of funds, the majority of the reward must be required by backers.

\subsection{Analysis of sufficient conditions}

After considering the necessary conditions, the next step in fsQCA is the analysis of sufficient conditions. Within this analysis, a truth table is constructed to identify all possible logical combinations of causal conditions that can lead to the outcome (or to the absence of the outcome). In total, there are $32\left(2^{5}\right.$, where 5 is the number of causal conditions used in the analysis) possible logical combinations (rows of the truth table). The truth table lists all possible logical combinations of causal conditions, along with the cases conforming to each combination. If rows have no cases, they are termed logical reminders and excluded from the analysis. To perform the analysis, a consistency cutoff must be set; here, consistency cut-offs of 0.811 and 0.758 have been adopted for the presence and the absence of the outcome, respectively.

Table 4 shows the intermediate solution of the fsQCA standard analysis. Three possible solutions exist: complex, parsimonious and intermediate. In Table 4, both the models for the presence and the absence of the outcome are presented. According to Schneider and Wagemann (2010), the solution consistency must be higher than 0.75 . Consequently, only the model for the absence of the outcome is deemed satisfactory, with a solution consistency of 0.778 . The solution coverage for the model regarding the absence of the outcome is high (0.789). This index explains the extent to which the four configurations of the model explain the data.

Table 4 also shows the configuration consistency, the raw consistency and the unique consistency. Configuration consistency measures the degree to which the configurations are subsets of the outcome, raw coverage measures the degree to which the configurations account for the outcome, and unique coverage explains the proportion of membership in the outcome explained solely by each individual configuration. 
Although the first model (a high level of funds raised) is not satisfactory according to Schneider and Wagemann's (2010) criteria, it is relevant to underline that all the combinations have a consistency higher than 0.75 , as required by Rihoux and Ragin (2009). Moreover, all combinations exhibit a high coverage, mainly Configuration 1 (with a raw coverage of 0.53 ). Nevertheless, all the configurations belonging to this first model are excluded from the analysis because of the solution consistency result.

On the other hand, for the second model (a low amount of funds raised), four combinations exhibit a good consistency level (higher than 0.75 ) and three of these also have a high coverage ratio. Consequently, only Combinations $4-6$ are taken into consideration.

Both the conditions NP and REWNOUSED are present in all three combinations; the conditions REW and BACKNOREW are present in two of three paths.

According to Configuration 4, which represents $27.7 \%$ of cases, a low level of funds is raised when the project searching for funds is a for-profit project, few backers do not ask for a reward and the percentage of reward not required during the campaign is low.

According to Configuration 5, 28.6\% of cases leading to a low amount of funds raised occur when the project is a not-for-profit project, few rewards are offered, many of the backers do not ask for a reward and, finally, the percentage of reward not required during the campaign is low.

According to Configuration 6, 36\% of the cases leading to a low amount of funds raised occur when the project is a not-for-profit project, many backers take part in the round, many rewards are offered, and the percentage of reward not required during the campaign is low.

The absence of the condition BACKNOREW, which is also a necessary condition for raising a low amount of funds, is a critical element in the three combinations described.

\section{Discussion}

To perform an analysis of the potential for collaboration between the public sector, local communities, social investors and crowdfunding web platforms, a critical step is understanding the nature of the factors able to influence the collection of funds for civic projects. This study contributes to this topic by employing fsQCA to identify which conditions combine and lead to the achievement of a significant collection of funds for civic projects. The analysis has focused mainly on the nature 
of civic projects and on the role played by the presence of rewards in the campaign to investigate the attitude of backers towards rewards.

Since they are aimed at improving community wellbeing, civic projects searching for funds are usually regarded as charitable initiatives (Sedlitzky \& Franz, 2019; Wang et al., 2019). Nonetheless, two other aspects must be taken into consideration. First, civic projects have both a not-for-profit and a for-profit nature, since civic crowdfunding is also used by social entrepreneurs to fund their social enterprises; moreover, civic fundraising campaigns are often run on generic reward-based platforms, where rewards are normally provided.

In this context, and considering the theoretical background described above, five propositions were formulated. The first proposition, which postulated that 'The nature of the project (not-for-profit versus for-profit) in a civic crowdfunding round has implications for the result of the fundraising campaign in terms of the amount of funds raised', is supported by the results. Indeed, the nature of the project is a condition present in all configurations for the second model (absence of the outcome). Nevertheless, a conclusion on the direction of this impact cannot be univocal. In two out of three configurations, being a not-for-profit project represents a condition for collecting a smaller amount of funds. Since all the projects in the dataset were successful and not overfunded, these results also confirm the fact that not-for-profit initiatives need less funds in comparison with for-profit projects. On the other hand, in one configuration, the for-profit nature of a project is a condition that leads to a smaller collection of funds. These results do not concur with the studies of Pitschner and PitschnerFinn (2014) and Allison et al. (2015), who found that non-profit projects have a higher probability of success and receive higher average contributions compared to for-profit projects. It should also be noted that this study considers the nature of the project a critical condition, since previous academic research on civic crowdfunding had not given much to this (Lee et al., 2019; Brent \& Lorah 2019), focusing on the study of other drivers that can influence campaign success (among others, Brent \& Lorah, 2019; Doan \& Toledano, 2018; Hassna et al., 2018).

For the second proposition (focused on the number of backers involved in a civic crowdfunding project), the results show that the number of backers does not have a significant influence on obtaining the outcome; that is, it does not influence the level of funds raised. However, this condition is present in one of the configurations indicating that a large numbers of backers in a round results in a low level of funds being raised. This finding contradicts the work of Martinez-Climent et al. (2019), who propose that crowdfunding bases its success on the potential to bring together as many backers as possible interested in raising funds for a project. On the other hand, in the context of civic 
crowdfunding, the concept of 'crowd' is difficult to define 'since both the number of participants and the amount they donate can vary significantly' (Sedlitzky \& Franz, 2019, p. 36).

Regarding the third proposition (focused on the number of rewards), the results show that this condition is also not relevant to the level of funds raised. This condition is present in two of the configurations. One indicates that when few rewards are offered, a low level of funds is collected, while the other indicates the opposite; when many rewards are offered the level of funds obtained is low.

As far as the fourth proposition is concerned, the percentage of backers requiring no reward is also present in two of the configurations. However, similarly to the previous condition, it appears that these configurations are in opposite directions. Therefore, the results indicate that this condition is not relevant for obtaining funds. Other authors have previously stated that backers involved in civic crowdfunding campaigns generally expect non-financial or emotional rewards, as they are driven by a sense of commitment and belonging to local territories (De Falco et al., 2015; Lehner, 2013; McWade, 2012)

Finally, with respect to the fifth proposition, the results show that a low percentage of rewards not being used is a critical condition for all three configurations that lead to small amounts of funds being raised. Consequently, for small-sized civic fundraising rounds, the presence of a reward is a critical factor. This result is in contrast with the conclusion reached by Colasanti et al. (2018), in which the great majority of respondents to their questionnaire claimed they did not need a reward. Moreover, according to Configuration 4, which accounts for $27.7 \%$ of the cases, small for-profit civic fundraising rounds also tend to find a low percentage of backers that do not require a reward as a critical element. Backers of civic fundraising rounds seem to be interested in rewards; they ask for them, even though their choice seem not to be affected by the number of rewards (third proposition). These results are in line with Sedlitzky and Franz's (2019) conclusion that if a campaign is mainly supported by local communities, interest in rewards can be critical. Indeed, these authors have claimed that participation in a civic round is made with a high degree of awareness and 'this awareness primarily involves personal interest, with philanthropy playing a smaller role' (p. 38).

\section{Conclusion}

This work has focused on the factors that can explain the amount of funds raised in a civic campaign, to extend the existing knowledge of the mechanisms guaranteeing a collaborative approach between local governments, local communities and crowdfunding platforms. 
To do this, a fsQCA approach was adopted to study five factors that can impact the fundraising process for civic initiatives. The dataset used in this research comprises 40 successful civic projects funded on an Italian reward platform (Eppela) from 2016 to 2019. The results show that of the five factors studied, only two had an impact on the level of funds collected: the nature of the project and the percentage of non-required rewards.

With regard to the nature of the project, the results of this study identified the nature of the project (for-profit and not-for-profit) as relevant to the amount of funds raised, and suggest that not-for-profit initiatives need less funds in comparison with for-profit projects. This is in contrast to previous studies (Allison et al., 2015; Pitschner \& Pitschner-Finn, 2014), which have indicated that non-profit projects are more likely to be successful and to raise more funds. On the other hand, the present study has shown that that for small-sized civic crowdfunding rounds, rewards seem to play an important role. These results are in line with Sedlitzky and Franz's (2019) conclusion that if a campaign is supported primarily by local communities, interest in rewards is critical.

From a theoretical point of view, this study provides a comprehensive overview of civic crowdfunding, which has received less attention from academia compared to other types of crowdfunding. The results of the study highlight the complexity of the civic market, comprised of not-for-profit and for-profit initiatives, backed by people that cannot be considered pure donors. Moreover, the research employs an alternative methodology able to provide evidence of several different paths that leads to the same outcome, instead of the unique solution that is typically found in traditional quantitative approaches. The fsQCA approach adopted in this study is consistent with the complexity and the multifaceted nature of the civic market.

The most important implication of the study concerns the role played by rewards in civic rounds. Exploiting the potential for collaboration between the public sector, crowdfunding platforms and local communities implies an awareness of the strengths and weaknesses of a generic reward-based platform compared with a dedicated civic platform. In addition, it also implies the need to carefully consider the reward mechanism, including the number and the type of rewards used in civic fundraising rounds. Consequently, important managerial implications can be derived from this study for local governments to improve match-funding schemes, transparency, and bottom-up approaches to decision-making processes; for local communities to identify how to support critical projects; and for crowdfunding platforms to adopt viable and effective business models for managing civic fundraising rounds. 
It is important to also highlight the limitations of this research, which may serve as a starting point for further research. The dataset is comprised of projects drawn from a reward-based crowdfunding platform. Similar data from a dedicated civic crowdfunding platform are required to conduct a more in-depth analysis of the factors influencing civic fundraising rounds. Moreover, the dataset includes only successful projects. Therefore, no conclusions can be drawn on the factors for success; this would also require data on unsuccessful civic crowdfunding rounds.

As far as the conclusion on rewards is concerned, it is important to remember that only the number of rewards have been considered in this analysis. Further research should focus on the nature of rewards by exploring how material or immaterial/emotional rewards might influence the result of a campaign differently.

Dealing with the motivations of civic backers is outside the purpose of this research, but the findings show how the idea of assimilating civic crowdfunding with charitable mechanisms cannot be taken for granted. The results suggest the need for a more detailed investigation on the motivations of civic backers. Civic backers do not appear to act as pure donors, and the role played by rewards in influencing the decision to financially support a campaign is worthy of further investigation. 


\section{References}

Allison, T. H., Davis, B. C., Short, J. C., \& Webb, J. W. (2015). Crowdfunding in a prosocial microlending environment: Examining the role of intrinsic versus extrinsic cues. Entrepreneurship Theory and Practice, 39(1), 53-73.

Bacigalupi, M. (2019). Il 'civic crowdfunding' raccoglie miliardi di euro, ma deve basarsi su una comunità reale. https://www.che-fare.com/fundraising-progetti-civic-based-rigenerazione/. Accessed 5 February 2020.

Bernardino, S. J., \& Santos, J. F. (2016). Potential of civic crowdfunding to the intelligence of cities and social innovation: An exploratory study. 16 Conferencia da Associacao de Sistemas de Informacao, Porto, Portugal.

Brent, D. A., \& Chan, N. W. (2019). Local public goods and the crowding-out hypothesis: Evidence from civic crowdfunding. Economics Bulletin, 39(3), 2142-2154.

Brent, D. A, \& Lorah, K. (2019). The economic geography of civic crowdfunding. Cities, 90, 122130. https://doi.org/10.1016/j.cities.2019.01.036.

Burtch, G., Ghose, A., \& Wattal, S. (2013). An empirical examination of the antecedents and consequences of contribution patterns in crowd-funded markets. Information Systems Research, 24(3), 499-519.

Calic, G. \& Mosakowski, E. (2016). Kicking off social entrepreneurship: How a sustainability orientation influences crowdfunding success. Journal of Management Studies, 53(5), 738767.

Calic, G., \& Shevchenko, A. (2020). How signal intensity of behavioral orientations affects crowdfunding performance: The role of entrepreneurial orientation in crowdfunding business ventures. Journal of Business Research, 115, 204-220.

Charbit, C., \& Desmoulins, G. (2017). Civic crowdfunding: A collective option for local public goods? OECD Regional Development Working Papers 2017/02, OECD Publishing, Paris. http://dx.doi.org/10.1787/b3f7alc5-en.

Colasanti, N., Frondizi, R., \& Meneguzzo, M. (2018). Higher education and stakeholders' donations: Successful civic crowdfunding in an Italian university. Public Money \& Management, 38(4), 281-288. https://doi.org/10.1080/09540962.2018.1449471.

Crilly, D. (2010). Predicting stakeholder orientation in the multinational enterprise: A mid-range theory. Journal of International Business Studies, 42(5), 694-717.

Davies, R. (2014). Civic crowdfunding: Participatory communities, entrepreneurs and the political economy of place. Massachusetts Institute of Technology, Cambridge, MA. 
Davies, R. (2015). Three provocations for civic crowdfunding. Information, Communication \& Society, 18(3), 342-355.

De Falco, S., Volpe, E., \& Cucari, N. (2015). Civic crowdfunding e valore del territorio: Un'analisi empirica attraverso due piattaforme italiane. Economia e diritto del terziario, 1, 675-692.

Doan, M. A, \& Toledano, M. (2018), Beyond organization-centred public relations: Collective action through a civic crowdfunding campaign. Public Relations Review, 44, 37-46. http://dx.doi.org/10.1016/j.pubrev.2017.10.001.

European Crowdfunding Network (2018). Triggering participation: A collection of civic crowdfunding and match-funding experiences in the EU. https://eurocrowd.org/. Accessed 5 February 2020.

Falk, A. (2004). Charitable giving as a gift exchange: Evidence from a field experiment, IZA Discussion Paper, No. 1148, May.

Fiss, P. (2007). A set-theoretic approach to organizational configurations. Academy of Management Review, 32(4), 1180-1198.

Fiss, P. (2011). Building better causal theories: A fuzzy set approach to typologies in organization research. Academy of Management Journal, 54(2), 393-420.

Hassna, G., Burtch, G., Lee, C. H., \& Zhao, J. L. (2018). Understanding the role of lead donor types in civic crowdfunding. http://dx.doi.org/10.2139/ssrn.3175916.

Huarng, K. H., Hui-Kuang Yu, T., \& Rodriguez-Garcia, M. (2020). Qualitative analysis of housing demand using Google trends data. Economic Research-Ekonomska Istraživanja, 33(1), 20072017, https://doi.org/10.1080/1331677X.2018.1547205.

Hudik, M., \& Chovanculiak, R. (2018). Private provision of public goods via crowdfunding. Journal of Institutional Economics, 14(1), 1-22. https://doi.org/10.1017/S1744137417000169.

Hui, J. S., Greenberg, M. D., \& Gerber, E. M. (2014). Understanding the role of community in crowdfunding work. In: Proceedings of the 17th ACM conference on computer supported cooperative work \& social computing. Baltimore, MA, 62-74.

Hummel, D. J. (2016). Civic crowd-funding: A potential test of the voluntary theory of public finance for public capital goods. Journal of Public Budgeting, 28(2), 171-195. https://doi.org/10.1108/JPBAFM-28-02-2016-B002.

Josefy, M., Dean, T. J., Albert, L. S., \& Fitza, M. A. (2016). The role of community in crowdfunding success: Evidence on cultural attributes in funding campaigns to "Save the Local Theater". Entrepreneurship Theory and Practice, 41(2), 161-182. https://doi.org/10.1111/etap.12263. 
Lee, C. H., Bian, Y., Karaouzene, R., \& Suleiman, N. (2019). Examining the role of narratives in civic crowdfunding: Linguistic style and message substance. Industrial Management \& Data Systems, 119(7), 1492-1514. https://doi.org/10.1108/IMDS-08-2018-0370.

Lee, C. H., Zhao, J. L., \& Hassna, G. (2016). Government-incentivized crowdfunding for one-belt, one-road enterprises: Design and research issues. Financial Innovation, 2(2), 1-14.

Lehner, O. M. (2013). Crowdfunding social ventures: A model and research agenda. Venture Capital, 15(4), 289-311. https://doi.org/10.1080/13691066.2013.782624.

Lewellyn, K. B., \& Fainshimdt, S. (2017). Effectiveness of CEO power bundles and discretion context: Unpacking the "fuzziness" of the CEO duality puzzle. Organization Studies, 38(11), 1603-1624. https://doi.org/10.1177/0170840616685364.

Lv, Z., Rodríguez-García, M., \& Sendra-García, J. (2020). Does institutional quality affect the level of entrepreneurial success differently across the entrepreneurship distribution? Review of Managerial Science. https://doi.org/10.1007/s11846-020-00383-3.

Martínez-Climent, C., Costa-Climent, R., \& Oghazi, P. (2019). Sustainable financing through crowdfunding. Sustainability, 11, 934. doi:10.3390/su11030934.

McWade, W. (2012). The role for social enterprises and social investors in the development struggle. Journal of Social Entrepreneurship, 3(1), 96-112. https://doi.org/10.1080/19420676.2012.663783.

Miglietta, M., Parisi, E., Pessione, M., \& Servato, F. (2013). Crowdfunding and local governments: A financial opportunity for a new liaison with citizens. In: Proceedings of the 16th ToulonVerona Conference 'Excellence in Services', Slovenia, 29-30 August, 485-495.

Passeri, F. (2017). The European dimension of civic crowdfunding. European Crowdfunding Network. http://eurocrowd.org/. Accessed 5 February 2020.

Pitschner, S., \& Pitschner-Finn, S. (2014). Non-profit differentials in crowd-based financing: Evidence from 50,000 campaigns. Economics Letters, 123(3), 391-394. https://doi.org/10.1016/j.econlet.2014.03.022.

Ragin, C. (2008). Redesigning social inquiry: Fuzzy sets and beyond. University of Chicago Press.

Rihoux, B., Ragin, C. (2009). Configurational comparative methods. Sage.

Schneider, C. Q, \& Wagemann, C. (2006). Reducing complexity in Qualitative Comparative Analysis (QCA): Remote and proximate factors and the consolidation of democracy. European Journal of Political Research, 45, 751-786.

Schneider, C. Q., \& Wagemann, C. (2010). Standards of good practice in Qualitative Comparative Analysis (QCA) and fuzzy sets. Comparative Sociology, 9, 1-22. 
Schneider, C. Q, \& Wagemann, C. (2012). Set-theoretic methods for the social sciences: A guide to qualitative comparative analysis. Cambridge University Press.

Sedlitzky, R., \& Franz, Y. (2019). 'What if we all chip in?' Civic crowdfunding as alternative financing for urban development projects. Built Environment, 45(1), 26-44. https://doi.org/10.2148/benv.45.1.26.

STARTEED (2019) Il crowdfunding in Italia. www.starteed.com. Accessed 9 May 2020.

Stiver, A., Barroca, L., Petre, M., Richards, M., \& Roberts, D. (2015a). Civic crowdfunding: How do offline communities engage online? In: ACM International Conference Proceedings Series, Part F116867, 37-45.

Stiver, A., Barroca, L., Minocha, S., Richards, M., \& Roberts, D. (2015b). Civic crowdfunding research: Challenges, opportunities, and future agenda. New Media \& Society, 17(2), 249271.

Tomczak, A., Brem, A. (2013). A conceptualized investment model of crowdfunding. Venture Capital, 15(4), 335-359. https://doi.org/10.1080/13691066.2013.847614.

Wang, T., Li, Y., Kang, M., \& Zheng, H. (2019). Exploring individuals' behavioural intentions toward donation crowdfunding: Evidence from China. Industrial Management \& Data Systems, 119(7), 1515-1534. https://doi.org/10.1108/IMDS-10-2018-0451.

Zhao, H., Jin, B., Liu, Q., Ge, Y., Chen, E., Zhang, X., \& Xu, T. (2020). Voice of charity: Prospecting the donation recurrence \& donor retention in crowdfunding. IEEE Transactions on Knowledge and Data Engineering, 32(8), 1652-1665, doi: 10.1109/TKDE.2019.2906199. 


\section{Tables}

Table 1: Outcome and conditions: Description and codification

\begin{tabular}{llc}
$\begin{array}{l}\text { Outcome and } \\
\text { Conditions }\end{array}$ & Description & Codification \\
\hline OUT & Continuous variable that specifies the amount of funds raised & Fuzzy value \\
NP & Dichotomous variable that distinguishes between for-profit and not-for-profit projects & Crisp value \\
BACK & Continuous variable that specifies the number of backers & Fuzzy value \\
REW & Continuous variable that specifies the number of rewards & Fuzzy value \\
BACKNOREW & $\begin{array}{l}\text { Continuous variable that specifies the percentage of backers that do not require a } \\
\text { reward }\end{array}$ & Fuzzy value \\
REWNOUSED & Continuous variable that specifies the percentage of rewards not required by backers & Fuzzy value \\
\hline
\end{tabular}

Table 2: Thresholds for the calibration process

\begin{tabular}{lccc}
\hline & $\begin{array}{c}\text { Full } \\
\text { membership }\end{array}$ & $\begin{array}{c}\text { Crossover } \\
\text { point }\end{array}$ & $\begin{array}{c}\text { Full non- } \\
\text { membership }\end{array}$ \\
\hline OUT & 127,485 & 40,000 & 9,800 \\
NP & $1=$ not-for-profit project; 0 & for-profit project \\
BACK & 100 & 61 & 39 \\
REW & 12 & 7 & 6 \\
\hline
\end{tabular}

Table 3: Analysis of necessary conditions

\begin{tabular}{lcccc}
\hline \multirow{2}{*}{ Conditions } & \multicolumn{2}{c}{ Presence } & \multicolumn{2}{c}{ Absence } \\
\cline { 2 - 5 } NP & Consistency & Coverage & Consistency & Coverage \\
$\sim$ NP & 0.869589 & 0.529000 & 0.649655 & 0.471000 \\
BACK & 0.130411 & 0.238000 & 0.350345 & 0.762000 \\
$\sim$ BACK & 0.531507 & 0.503896 & 0.618391 & 0.698701 \\
REW & 0.682192 & 0.600000 & 0.560920 & 0.587952 \\
$\sim$ REW & 0.647671 & 0.532432 & 0.721839 & 0.707207 \\
BACKNOREW & 0.643836 & 0.660112 & 0.522759 & 0.638764 \\
$\sim$ BACKNOREW & 0.850873 & 0.560015 & 0.845049 & 0.662847 \\
REWNOUSED & 0.384524 & 0.882222 & 0.256271 & 0.700730 \\
$\sim$ REWNOUSED & 0.869561 & 0.495216 & 0.956926 & 0.649485 \\
\hline
\end{tabular}


Table 4: Analysis of sufficient conditions: The intermediate solution

\begin{tabular}{lccc|cccc}
\hline & \multicolumn{3}{c}{ Presence } & \multicolumn{5}{c}{ Absence } \\
Configuration no. & 1 & 2 & 3 & 4 & 5 & 6 & 7 \\
\hline NP & $\bullet$ & $\bullet$ & $\bullet$ & $\otimes$ & $\bullet$ & $\bullet$ & $\bullet$ \\
BACK & & $\otimes$ & & & & $\bullet$ & $\otimes$ \\
REW & $\otimes$ & $\bullet$ & & & $\otimes$ & $\bullet$ & $\bullet$ \\
BACKNOREW & & & $\bullet$ & $\otimes$ & $\bullet$ & & $\otimes$ \\
REWNOUSED & $\otimes$ & & $\otimes$ & $\otimes$ & $\otimes$ & $\otimes$ & $\bullet$ \\
\hline Raw coverage & 0.534 & 0.387 & 0.430 & 0.277 & 0.286 & 0.360 & 0.156 \\
Unique coverage & 0.116 & 0.086 & 0.021 & 0.277 & 0.089 & 0.175 & 0.037 \\
Consistency & 0.778 & 0.776 & 0.823 & 0.838 & 0.789 & 0.760 & 0.773 \\
Solution coverage & & 0.679 & & & & 0.789 & \\
Solution consistency & & 0.720 & & & & 0.778 & \\
\hline
\end{tabular}

Note: The symbol ' $\otimes$ ' means absence of the condition and ' $\bullet$ ' means presence of the condition. Blank spaces indicate a do not care condition (Fiss, 2011). 